\title{
ENSAIO CLINICO COM UM NEUROLÉPTICO (TIOTIXENE)
}

\author{
SÉRgio Traldi *
}

No atual estágio da psicofarmacologia deve-se buscar a especificação de quais os sintomas ou sinais influenciados pela ação de determinada droga para poder fazer indicação terapêutica seletiva. Esta conduta é bem justificada no trabalho de Hertrich ${ }^{4}$ que, baseado em grande literatura, conclui fornecendo certas regras consideradas indispensáveis não apenas para o tratamento adequado das perturbações mentais, mas também para que os trabalhos de experimentação clínica possam ter significado para auxiliar o conhecimento mais completo das drogas. Para Hertrich os trabalhos que dão conta apenas de melhoras globais da moléstia não aumentam o nosso conhecimento e não permitem conclusões de interêsse. Este autor relembra que o tratamento com drogas psicotrópicas é sintomático, permitindo apenas suspeitar que sejam realmente atingidos pontos nucleares. funcionais da moléstia. Portanto, a descrição adequada e minuciosa da sintomatologia é atualmente indispensável para a avaliação dos resultados. Baseado na atuação dos medimentos sôbre determinados sintomas, será possivel a associação de drogas, bem como a alternância ou substituição das mesmas durante o tratamento, de acôrdo com a evoluçāo do caso.

\section{MATERIAL E MÉTODO}

Utilizamos o P-4657B (Tiotixene) ** que é um derivado de tioxanteno relacionado à tioproperazina que, por sua vez, é um derivado piperazinico da fenotiazina, classe de compostos cujo advento é marcado pela prometazina, prosseguindo com as drogas anti-psicóticas inicialmente empregadas, tais como a clorpromazina e a promazina. A síntese do $\mathrm{P}-4657 \mathrm{~B}$ visou à obtenção de droga que tivesse a mesma ação anti-psicótica da tioproperazina porém desacompanhada dos efeitos colaterais principalmente relacionados ao tracto extrapiramidal ${ }^{\circ}$.

O P-4657B (Tiotixene) é um isômero do 2-dimetil-sulfamil-[9-(4-metil-1-piperazinjl)propiledeno]tioxanteno, insolúvel em água. Da mesma forma que a tioproperazina, o P-4657B é um potente anti-emético em experimentaçāo com o cão. Tem propriedades anti-colinérgicas, anti-histaminicas, hipotensoras e hipotérmicas muito fracas em animais. Como não dispusemos da forma injetável do produto, todos os casos foram tratados, desde $o$ inicio, com o produto administrado por via oral. A via parenteral seria útil no tratamento da fase inicial das sindromes agudas.

Na seleção dos pacientes procuramos evitar a inclusão de pacientes com idades extremas; o mais jovem tinha 22 e o mais idoso 53 anos de idade, com a média de 33,92 anos. Excluimos os que apresentavam problemas clínicos, os que

Trabalho do Hospital de Juqueri, apresentado ao Centro de Estudos Franco da Rocha em 26-7-67: * Psiquiatra do Departamento de Assistencia a Psicopatas do Estado de Sāo Paulo.

* Medicamento fornecido pela Pfizer Quimica Ltda. 
tinham grande rebaixamento global da personalidade, assim como os sofredores de formas mistas de psicose ou que se tivessem mostrado extremamente sensiveis (em relação a efeitos colaterais) aos neurolépticos de modo geral. Trabalhamos sòmente com doentes rotulados dentro das psicoses esquizofrênicas, enquadráveis no item 8 da Classificação Brasileira de Moléstias Mentais de 1948 . Não nos preocupamos com a distinçáo diagnóstica dos tipos ou subtipos. Todos os pacientes estavam internados na 5.a Colónia de Homens do Hospital Psiquiátrico de Juqueri e sòmente dois dêles tinham tempo de inicio da doença inferior a dois anos.

Para a avaliaçāo do efeito terapêutico adotamos um critérto misto, ou seja, em primeiro lugar, pela descrição dos sintomas alterados, normalizados ou plorados e, secundàriamente, pelo aspecto global da melhora obtida. Em função dēste segundo critério, a avaliação foi baseada nos seguintes itens: a) inalterado quando, após a administração do medicamento por 60 dias, no máximo da dose tolerada pelo paciente, não houve melhora apreciável do quadro mental; b) melhora parcial quando, após a admínistração do medicamento por 60 dias no máximo de posologia suportável pelo paciente, houve atenuação ou desaparecimento de alguns sintomas, ou recuperacão de algumas faculdades, porém ainda insuficientes para permitirem a ressocialização do paciente; c) remissão social quando, após a administração da droga por 60 dias na dosagem maior tolerada pelo paciente, ocorreram melhoras clinicas suficientes para permitir a alta hospitalar e a ressocialização do paciente.

Empregamos o seguinte esquema quanto à posologia: começamos por administrar $7,5 \mathrm{mg}$ diăriamente, aumentando meio comprimido por dia até o décimo dia, sendo a última dosagem ( $30 \mathrm{mg}$ ) mantida durante 10 dias. Os pacientes que nāo tinham mostrado sinais de parkinsonismo ou que nāo tinham se beneficiado passaram a segunda fase, com aumento diário de meio comprimido até a dose de $60 \mathrm{mg}$. A partir de então, para os que nāo haviam mostrado sinais de impregnação ou apresentado melhoras clínicas, as doses foram acrescidas de meio comprimido diário até o máximo de $80 \mathrm{mg}$ diárias. Estabilizávamos a dosagem assim que surgissem os sinais indicativos de impregnação do sistema nervoso central. Esta conduta não se baseou, evidentemente, no pretenso paralelismo que alguns autores admitem entre efeito terapéutico e sinais de parkinsonismo, mas sim na observacão de que os efeitos terapêuticos máximos se aproximavam da dose de impregnaçăo. A dose diária máxima empregada foi de $80 \mathrm{mg}$ e o têrmo médio da dose de impregnação situou-se em $58,3 \mathrm{mg}$ diàriamente (10 $\mathrm{mg} \mathrm{em}$ um, $25 \mathrm{mg}$ em um, $45 \mathrm{mg}$ em 6, $60 \mathrm{mg}$ em $5,70 \mathrm{mg}$ em $8,75 \mathrm{mg}$ em um e $80 \mathrm{mg}$ em dois casos). Năo usamos qualquer outro recurso terapêtico durante tôda a experimentação (90 dias). Após o estabelecimento da posologia de manutençāo, seguimos a técnica do "double-blind", administrando a cada metade dos pacientes, respectivamente, a droga e o placebo.

Em nenhum caso fomos obrigados a interromper o tratamento por fenômenos colaterais intensos, por intolerância à droga ou por moléstias intercorrentes. Sòmente em um caso fomos obrigados a administrar medicamentos anti-parkinsonianos.

Seguimento clinico-laboratorial - Após o exame clínico, foram colhidos materiais para exames de contrôle (hemograma, pesquisa de proteinúria e glicosúria, exame do sedimento urinário e dosagem de transaminases). O contrôle hemático mediante hemograma não mostrou alterações da crase sangüinea; em apenas três casos ocorreu aparecimento de granulaçōes tóxicas em polinucleares neutrófilos. Da mesma forma, a função renal não foi alterada. Embora as transaminases mostrassem tendência à elevacão no final do tratamento, mantiveram seus niveis dentro dos padrōes considerados como normais. $O$ contrôle do pêso corporal foi feito cada 7 dias; nenhum dos pacientes perdeu pêso havendo, pelo contrário, um aumento global de $4,7 \%$. As tomadas de pressão arterial, do pulso e de temperatura foram feitas diăriamente, não sendo observadas alterações dignas de menção. 


\section{RESULTADOS}

Sem preocupação maior com o diagnóstico da forma do processo esquizofrènico, estudamos 24 casos, obtendo os seguintes resultados, segundo o aspecto global: inalterados em 3; melhoras parclais em 9; remissão social em 12 casos.

Após o seguimento durante um mês, com os pacientes divididos em dois gru. pos, um dos quais continuou tomando o medicamento em dose de manutençāo e outro apenas placebo, constatamos a manutenção dos resultados em todos os casos (100\%) do primeiro grupo; no segundo grupo ocorreram 5 recidivas $(41,6 \%)$.

Se englobarmos os casos que foram benèficamente influenciados pela droga (9 melhoras parciais e 12 remissōes sociais) teremos um total de 21, ou seja, $84 \%$. Esses resultados se aproximam bastante dos conseguidos por outros autores.

\section{COMENTARIOS}

Todos os investigadores que trabalharam com o Tiotixene concordam ser o mesmo um potente agente neuroléptico com alguma ação sedativa particularmente apreciável no comêço do tratamento, mas não suficientemente forte para acalmar pacientes agitados. E provável que uma forma de administração parenteral fôsse útil nessa eventualidade. $O$ Tiotixene primeiramente melhora o contacto social e diminui as tensões internas, a agitação, a excitação e a agressividade; as alucinações e a estruturação delirante são influenciadas tambẻm, mas em fase ulterior, enquanto que a desagregação do pensamento, a depressão e a estruturação psicótica são fracamente influenciadas. Assim, o P-4657B seria droga particularmente indicada em esquizofrênicos crônicos abúlicos e apragmáticos.

Delay e col. ${ }^{1}$ notaram um efeito anti-psicótico potente com ação sedativa minima ou sòmente temporária. Observaram também, um poder desinibitório na maioria dos pacientes psicóticos desagregados e concluiram pela ausência de efeito anti-alucinatório específico e fracasso em estados mania$\cos$ e nas grandes agitaçōes psicóticas. Gann ${ }^{2}$ tratou 30 casos, notando fraca resposta com $5 \mathrm{mg}$; entretanto, com $10 \mathrm{mg}$, durante a segunda semana, a agitação e a agressividade diminuiram; na quarta semana, com a dose de $20 \mathrm{mg} /$ dia, a ansiedade e a desconfiança cederam; até êsse momento a ação sôbre as alucinações e a dissociação da personalidade foi fraca; após 16 semanas, nos casos que reagiram bem (14), a agitaçāo, a agressividade e a excitação desapareceram, o ajustamento social melhorou, as alucinações e os delírios diminuiram. Gomez Martinez ${ }^{3}$ observou sedação, caracterizada por melhor adaptação ao meio hospitalar e melhor contacto social, havendo boa influência também em relaçāo à agitação e à excitação; em muitos pacientes notou atuação sôbre o autismo, agressividade e alucinações; os delírios foram pouco influenciados e não houve influência sôbre a dissociação do pensamento ou sôbre a rigidez afetiva.

Em nossa experimentação observamos uma ação surpreendente do Tiotixene sôbre o componente conativo. Pacientes que, submetidos a tôdas as terapêuticas até agora conhecidas, permaneciam apáticos, abúlicos, totalmente desinteressados em relação ao meio, passaram a cuidar de sua aparência pessoal, a procurar atividade útil, a se interessar pelo seu futuro 
e pelos familiares. Notamos, inclusive, que essa atividade surgia mesmo quando o paciente ainda tinha distúrbios senso-perceptivos ou certa atividade delirante. A "leucotomia farmacológica" ocorre com a administração do Tiotixene: o paciente está alucinado ou delirante mas não sofre, não tem vivência de seus distúrbios.

Verificamos o fraco poder anti-alucinatório do $\mathrm{P}-4657 \mathrm{~B}$, o que nos permite sugerir seu uso associado, concomitantemente, precedendo ou seguindo a algum outro neuroléptico cuja ação seja mais evidente nesse sentido.

Analisando os nossos resultados comprova-se a real atividade do produto e a necessidade de prosseguir-se no tratamento com uma dose de manutenção. A terceira conclusão, também válida para os outros neurolépticos, é que o efeito terapêutico tem apenas caráter sintomático.

Embora tenhamos obtido resultados que permitem considerar o Tiotixene como particularmente indicado em pacientes esquizofrênicos crônicos cujo quadro seja caracterizado predominantemente pela abulia e pelo apragmatismo, julgamos que seu uso em associação ou em alternância com outros neurolépticos possa dar maior amplitude de melhora em pacientes cujo componente conativo não tenha se beneficiado completamente. Não há, em todo arsenal terapêutico dos psicotrópicos, medicação que consiga abranger todos os aspectos psicopatológicos. $\hat{E}$ o conhecimento da especificidade da ação de um determinado fármaco que o elege para ser empregado em um caso particular, pois que a tendência dos pesquisadores vem sendo a de buscar uma especificidade de ação cada vez maior.

Conclusões - (1) O Tiotixene tem ação antipsicótica nitida atuando preferentemente sôbre o componente conativo; (2) é fraco anti-alucinatório e sua ação sôbre a problemática delirante não é uniforme; (3) é altamente inócuo, não senđo observađas alterações de crase sangüínea, da função renal ou hepática, não determinando hipotensão ortostática nem alterações sensiveis da freqüência cardíaca; (4) produz os sinais da reação parkinsonóide ou de pseudoparkinsonismo, em doses variáveis entre 10 e $80 \mathrm{mg}$ diárias; (5) a curva ponderal global alterou-se, com aumento de 4,7\%.

\section{RESUMO}

$O$ autor relata os resultados obtidos com o P-4657B (Tiotixene) em 24 pacientes internados no Hospital Psiquiátrico de Juqueri, todos com esquizofrenia, enquadráveis no item 8 da Classificação Brasileira de Moléstias Mentais de 1948. Referindo ter obtido $84 \%$ de resultados globais favoráveis, analisa os resultados terapêticos, salientando a grande especificidade de ação do produto sôbre a esfera conativa. A parte final da pesquisa é efetuada com o método duplamente cego, mostrando a necessidade de seguimento com dose de manutenção e o aspecto sintomático das melhoras obtidas. 


\section{SUMMARY}

\section{Ctinical trial with a neuroleptic drug: Thiothixene}

The author describes the results obtained with P-4657B (Thiothixene) in 24 patients of the Psychiatric Hospital of Juqueri. The therapeutic effects are analysed and the product's great specific action in the connatal field is stressed, with a global $84 \%$ of favourable results. The final part of the trial concerns a double-blind study, the necessity of maintenance doses and the symptomatic improvement being emphazised.

\section{REFERENCIAS}

1. DELAY, J.; DENICKER, P.; GINESTET, D.; PERIER, M.; PERON-MAGNAN, P. \& DALLE, B. - Evaluation clinique precoce d'une nouvelle formule neuroleptique: le Thiothixene. Ann. Medico-Psychol. 2:196, 1966.

2. GANN, G. - A clinical evaluation with Thiothixene in chronic schizophrenic patients. Resumo in Excerpta Medica 117:193, 1966.

3. GOMEZ MARTINEZ, J. - Experiência clinica com Tiotixene un nuevo neuroleptico. Resumo in Excerpta Medica 117:207, 1966.

4. HERTRICH, O. - Differentialindikationen für Psychossenspezifische Drogen nach Zielsymptomen. Fortsch. Neurol. u. Psychiat. 33:49, 1965.

5. SIGNORINI, J.; VIEIRA, N. C.; ASSIS, L. M. \& MARTINS, C. - Ensaio clinico com o P-4657B em pacientes hospitalizados Arq. Neuro-Psiquiat. (São Paulo) 25:124, 1967.

6. TRALDI, S. - Emprêgo do enantato de tilufenazina em esquizofrênicos crônicos. Fôlha Médica 53:105, 1966.

Hospital de Juqueri - Franco da Rocha, SP - Brasil. 